\title{
Statistical Constitutive Model of Thermal Damage for Deep Rock considering Initial Compaction Stage and Residual Strength
}

\author{
Lingjie Zhu, ${ }^{1,2}$ Xiaoli Xu ${ }^{(D)},{ }^{1,3}$ Xiaojian Cao, ${ }^{1}$ and Shaoyong Chen $\mathbb{D}^{1}$ \\ ${ }^{1}$ School of Transportation and Civil Engineering, Nantong University, Nantong 226019, China \\ ${ }^{2}$ School of Science, Nantong University, Nantong 226019, China \\ ${ }^{3}$ State Key Laboratory for Geomechanics and Deep Underground Engineering, China University of Mining and Technology, \\ Xuzhou 221008, China
}

Correspondence should be addressed to Xiaoli Xu; xuxiaoli@ntu.edu.cn

Received 3 June 2019; Revised 8 July 2019; Accepted 15 July 2019; Published 25 July 2019

Academic Editor: Xiao-Qiao He

Copyright (C) 2019 Lingjie Zhu et al. This is an open access article distributed under the Creative Commons Attribution License, which permits unrestricted use, distribution, and reproduction in any medium, provided the original work is properly cited.

From the theory of damage mechanics, based on the Hoek-Brown strength criterion and Weibull distribution law of rock microelement strength, a statistical constitutive model of rock thermal damage is established by using equivalent strain hypothesis, and the theoretical model is modified by considering the compression coefficient and residual strength correction coefficient. The rationality of the modified model is verified by experimental data. The results show that the stress-strain curves of rock can be divided into four stages: initial compaction, stable damage propagation, damage strengthening expansion, and damage failure according to the characteristics of rock damage evolution. The peak stress of rock increases exponentially with the increase of confining pressure, and the maximum damage evolution rate decreases exponentially with the increase of confining pressure, which indicates that confining pressure delays the development of cumulative damage. The peak stress and maximum damage evolution rate of rock decrease exponentially with the increase of temperature, which accelerates the damage of rock. The initial damage of rock is thermal damage caused by temperature, and the damage value increases with the increase of temperature. The revised theoretical curve reflects the characteristics of rock compaction stage and residual strength and improves the coincidence with the experimental curve. The research results provide a reference for the establishment of thermal damage constitutive model of rock in deep engineering.

\section{Introduction}

With the shortage of shallow resources, energy is continuously exploited in deep areas. The deep rock has the unique characteristics of high in situ stress, high temperature, and high permeability pressure. The shallow rock constitutive relationship does not take into account the influence of temperature and confining pressure, which leads to the current engineering practice greatly ahead of the basic theory research, and the blindness of its engineering activities has caused a large number of casualties. Therefore, the establishment of constitutive models for thermal damage of deep rock under different temperatures and pressures has become an important subject in rock mechanics research.

At present, many researchers have done a lot of studies on rock damage constitutive model. For example, Cao et al. [1] discussed the statistical damage constitutive model of rock based on Weibull distribution, assuming the characteristics of rock microelement strength obeying Weibull distribution. Fang [2] hypothesized that the microelement strength of rock followed lognormal distribution and discussed the rock damage constitutive model based on Mohr-Coulomb (M-C) criterion. However, the M-C criterion is applicable to the rock strength under lower stress, while under higher stress, rock strength will produce greater errors.

$\mathrm{Xu}$ et al. [3] established the constitutive equation of rock softening damage based on Drucker-Prager (D-P) failure criterion, which reflects the stress-strain relationship of rock. Because the D-P criterion is conservative, the rationality of rock microelement strength determined by this criterion is limited. Hoek-Brown (H-B) strength criterion reflecting intrinsic characteristics of rock mass was established by Hoek 
and Brown et al. [4], which can explain the influence of low stress zone and tensile stress. H-B criterion is more suitable for rock mass materials than $\mathrm{M}-\mathrm{C}$ criterion because it takes into account rock strength related to confining pressure [5]. Yu et al. [6] discussed the feasibility of strength parameter estimation of deep engineering rock mass based on H-B strength criterion and rock mass mechanical parameter estimation method. In addition, more scholars $[7,8]$ have found that the $\mathrm{H}-\mathrm{B}$ criterion can reflect the failure characteristics of rocks and has been widely promoted and applied in practical rock mass engineering. In terms of considering the rock temperature effect, Zhang [9] studied the damage evolution of mudstone under the action of high temperature and preliminarily established the creep constitutive model of mudstone considering the temperature effect, which enriched the basic theory of rock mechanics. Meng et al. [10] established a rock damage model considering freeze-thaw effect and discussed the total damage variables under freeze-thaw load from the aspects of damage area and microelement damage. Xia et al. [11, 12] believed that under the action of temperature, the linear expansion coefficient of each component in the rock is different, which leads to the thermal stress between particles. When the thermal stress exceeds a certain strength, new defects will be generated, and the thermal damage in the rock will be generated and developed.

Since the rock has the initial compaction stage, and the residual strength gradually becomes the main factor affecting the strength of the postpeak stage of the rock with the increase of confining pressure, so the thermal damage constitutive model of the rock considering the initial compaction stage and residual strength should be established. Li et al. [13, 14] introduced the initial damage coefficient and established the rock damage constitutive model modified based on the initial damage coefficient. Cai et al. [15] studied the residual strength characteristics of rock mass through numerical simulation of strength test. Wen et al. [16] established the damage constitutive model based on rock strain analysis and proposed the damage evolution equation reflecting the initial damage of rock and the determination method of each parameter of the model. Xu et al. [17] established the constitutive model of rock thermal damage, but the influence of residual strength was not considered.

In view of the current research, there are few studies on the constitutive model of thermal damage of rock considering initial compaction and residual strength simultaneously. Therefore, rock compaction coefficient and residual strength correction coefficient are introduced in established thermal damage constitutive model of deep rock, which can reflect the initial compaction and residual strength characteristics of rock, and provide reference for deep rock engineering.

\section{Thermal Damage Evolution Equation of Rock}

2.1. Damage Variables $D_{M}$ Caused by Loading. Considering the randomness of internal defects in rock materials, the damage constitutive model of rock is studied by statistical method. Assuming that the failure of rock satisfies Weibull distribution, its probability statistical density is [18]

$$
P(F)=\frac{a}{F_{0}}\left(\frac{F}{F_{0}}\right)^{a-1} \exp \left[-\left(\frac{F}{F_{0}}\right)^{a}\right]
$$

where $P(F)$ is the strength probability of rock at strain $\varepsilon, a$ and $F_{0}$ are the morphological parameters of Weibull distribution, and $F$ is the random distribution variable in Weibull.

Deformation and failure of rock is a continuous process of continuous damage in material. Rock damage variable $D_{M}$ can be defined as follows:

$$
D_{M}=\frac{N_{t}}{N}
$$

where $N_{t}$ is the number of destroyed microelements and $N$ is the total number of microelements.

When the load is loaded to $F$, the number of destroyed microelements is

$$
N_{t}(F)=\int_{0}^{F} N P(F) d F=N\left\{1-\exp \left[-\left(\frac{F}{F_{0}}\right)^{a}\right]\right\}
$$

When (3) is substituted for (2), there are

$$
D_{M}=1-\exp \left[-\left(\frac{F}{F_{o}}\right)^{a}\right]
$$

It is assumed that the ultimate principal stress in rock mass failure meets the H-B strength criterion [4]; that is,

$$
\begin{aligned}
F\left(\sigma^{*}\right)= & m \sigma_{c} \frac{I_{1}^{*}}{3}+4 J_{2}^{*} \cos ^{2} \theta_{\sigma} \\
& +m \sigma_{c} \sqrt{J_{2}^{*}}\left(\cos \theta_{\sigma}+\frac{\sin \theta_{\sigma}}{\sqrt{3}}\right)=s \sigma_{c}^{2}
\end{aligned}
$$

where $\sigma_{c}$ is uniaxial compressive strength; $m$ and $s$ are material constants; $\theta_{\sigma}$ is Lode angle; $I_{1}^{*}$ is the first invariant of effective stress; and $J_{2}^{*}$ is the second invariant of effective stress deviation.

For traditional triaxial tests, $\sigma_{1}>\sigma_{2}=\sigma_{3}, \theta_{\sigma}=30^{\circ}$ [4], there are

$$
I_{1}^{*}=\frac{E \varepsilon_{1}\left(\sigma_{1}+2 \sigma_{3}\right)}{\sigma_{1}-2 \mu \sigma_{3}}
$$




$$
\sqrt{J_{2}^{*}}=\frac{\left(\sigma_{1}-\sigma_{3}\right) E \varepsilon_{1}}{\sqrt{3}\left(\sigma_{1}-2 \mu \sigma_{3}\right)}
$$

where $\sigma_{1}$ is the maximum principal stress; $\sigma_{3}$ is the minimum principal stress; $E$ is the modulus of elasticity; $\varepsilon_{1}$ is the axial strain; and $\mu$ is Poisson's ratio.

Substituting (6) and (7) into (5), we can obtain

$$
F\left(\sigma^{*}\right)=\frac{m \sigma_{1} \sigma_{c} E \varepsilon_{1}}{\sigma_{1}-2 \mu \sigma_{3}}+\frac{\left[\left(\sigma_{1}-\sigma_{3}\right) E \varepsilon_{1}\right]^{2}}{\left(\sigma_{1}-2 \mu \sigma_{3}\right)^{2}}
$$

According to (4) and (8), the mechanical damage $D_{M}$ caused by load is as follows:

$$
\begin{aligned}
& D_{M} \\
& =1 \\
& \quad-\exp \left\{-\left[\frac{m \sigma_{c} \sigma_{1} E \varepsilon_{1}}{F_{0}\left(\sigma_{1}-2 \mu \sigma_{3}\right)}+\frac{\left(\sigma_{1}-\sigma_{3}\right)^{2} E^{2} \varepsilon_{1}^{2}}{F_{0}\left(\sigma_{1}-2 \mu \sigma_{3}\right)^{2}}\right]^{a}\right\}
\end{aligned}
$$

2.2. Thermal Damage Variable $D_{T}$ Caused by Temperature. When the temperature of rock changes, thermal stress will occur inside the rock, which will lead to the gradual expansion of microcracks and the change of elastic modulus, thus affecting the mechanical properties of rock. The rock failure caused by microcracks caused by temperature can be expressed by thermal damage $D_{T}$. According to the macro damage mechanics theory, thermal damage can be characterized by rock mechanical parameters [19], and its thermal damage variable is defined as

$$
D_{T}=1-\frac{E_{T}}{E_{0}}
$$

where $E_{0}$ is the elastic modulus of rock at room temperature and $E_{T}$ is the elastic modulus of rock at temperature $T$.

2.3. Total Damage Evolution Equation of Rock. Thermal stress is generated by the change of temperature in rocks, and the thermal expansion of particles in rocks leads to the expansion of microcracks. Under the action of load, the particles of rocks slide in a dislocation with each other, and the resulting damage changes the mechanical properties of rocks. Considering the coupling effect of temperature and load, the total rock damage variable $D$ under high temperature is defined as [20]

$$
D=D_{T}+D_{M}-D_{T} D_{M}
$$

By substituting (9) and (10) into (11), the total damage evolution equation of rock can be obtained as follows:

$$
\begin{aligned}
D & =1-\frac{E_{T}}{E_{0}} \\
& \cdot \exp \left\{-\left[\frac{m \sigma_{c} \sigma_{1} E \varepsilon_{1}}{F_{0}\left(\sigma_{1}-2 \mu \sigma_{3}\right)}+\frac{\left(\sigma_{1}-\sigma_{3}\right)^{2} E^{2} \varepsilon_{1}^{2}}{F_{0}\left(\sigma_{1}-2 \mu \sigma_{3}\right)^{2}}\right]^{a}\right\}
\end{aligned}
$$

By differentiating (12), the equation of rock damage evolution rate can be obtained as follows:

$$
\begin{aligned}
\frac{d D}{d \varepsilon_{1}} & =\frac{a}{F_{0}} \frac{E_{T}}{E_{0}} \\
\cdot & \exp \left\{-\left[\frac{m \sigma_{c} \sigma_{1} E \varepsilon_{1}}{F_{0}\left(\sigma_{1}-2 \mu \sigma_{3}\right)}+\frac{2 \varepsilon_{1} E^{2}\left(\sigma_{1}-\sigma_{3}\right)^{2}}{F_{0}\left(\sigma_{1}-2 \mu \sigma_{3}\right)^{2}}\right]^{a}\right\} \\
\cdot & {\left[\frac{m \sigma_{c} \sigma_{1} E \varepsilon_{1}}{F_{0}\left(\sigma_{1}-2 \mu \sigma_{3}\right)}+\frac{\left(\sigma_{1}-\sigma_{3}\right)^{2} E^{2} \varepsilon_{1}^{2}}{F_{0}\left(\sigma_{1}-2 \mu \sigma_{3}\right)^{2}}\right]^{a-1} } \\
. & {\left[\frac{m \sigma_{c} \sigma_{1} E}{\sigma_{1}-2 \mu \sigma_{3}}+\frac{2 \varepsilon_{1} E^{2}\left(\sigma_{1}-\sigma_{3}\right)^{2}}{\left(\sigma_{1}-2 \mu \sigma_{3}\right)^{2}}\right] }
\end{aligned}
$$

Under uniaxial compression, $\sigma_{2}=\sigma_{3}=0$, (13) can be simplified as follows:

$$
\begin{aligned}
\frac{d D}{d \varepsilon_{1}}= & \frac{a}{F_{0}} \cdot \frac{E_{T}}{E_{0}} \cdot \exp \left[-\left(\frac{m \sigma_{c} E \varepsilon_{1}}{F_{0}}+\frac{E^{2} \varepsilon_{1}^{2}}{F_{0}}\right)^{a}\right] \\
& \cdot\left(\frac{m \sigma_{c} E \varepsilon_{1}}{F_{0}}+\frac{E^{2} \varepsilon_{1}^{2}}{F_{0}}\right)^{a-1} \cdot\left(m \sigma_{c} E+2 \varepsilon_{1} E^{2}\right)
\end{aligned}
$$

\section{Thermal Damage Statistical Constitutive Model of Rock}

3.1. Thermal Damage Constitutive Model. According to Lemaitre strain equivalence hypothesis [21],

$$
\sigma=\sigma^{*}(1-D)
$$

where $\sigma$ is the nominal stress of rock and $\sigma^{*}$ is the effective stress of rock.

The effective stress $\sigma^{*}$ is

$$
\sigma_{i}^{*}=E \varepsilon_{i}+\mu\left(\sigma_{j}^{*}+\sigma_{k}^{*}\right)
$$

where $\varepsilon_{i}$ is the effective strain.

Combined with (3), (8), and (16), the statistical constitutive equation of rock thermal damage can be obtained as follows:

$$
\begin{aligned}
\sigma_{1} & =E_{T} \varepsilon_{1} \\
& \cdot \exp \left\{-\left[\frac{m \sigma_{c} \sigma_{1} E_{T} \varepsilon_{1}}{F_{0}\left(\sigma_{1}-2 \mu \sigma_{3}\right)}+\frac{\left(\sigma_{1}-\sigma_{3}\right)^{2} E_{T}^{2} \varepsilon_{1}^{2}}{F_{0}\left(\sigma_{1}-2 \mu \sigma_{3}\right)^{2}}\right]^{a}\right\} \\
& +\mu\left(\sigma_{2}+\sigma_{3}\right)
\end{aligned}
$$

3.2. Determination of Model Parameter $\left(F_{0}, a\right)$. By introducing characteristic parameters such as peak strength and peak strain, when the axial stress of rock reaches its peak value, $\varepsilon_{f}$ and $\sigma_{f}$ should satisfy the following geometric conditions (see Figure 1):

$$
\text { (1) } \begin{aligned}
\varepsilon_{1} & =\varepsilon_{f}, \\
\sigma_{1} & =\sigma_{f}
\end{aligned}
$$


(2) $\varepsilon_{1}=\varepsilon_{f}$,

$$
\frac{d \sigma_{1}}{d \varepsilon_{1}}=0
$$

where $\varepsilon_{f}$ and $\sigma_{f}$ are peak strain and peak stress of rock, respectively.

The partial differential of (17) is obtained and simplified:

$$
a=\frac{F}{\varepsilon_{1}\left\{m \sigma_{1} \sigma_{c} E /\left(\sigma_{1}-2 \mu \sigma_{3}\right)+2 \varepsilon_{1}\left[\left(\sigma_{1}-\sigma_{3}\right) E\right]^{2} /\left(\sigma_{1}-2 \mu \sigma_{3}\right)^{2}\right\} \cdot \ln \left(E \varepsilon_{1} /\left(\sigma_{1}-2 \mu \sigma_{3}\right)\right)}
$$

After taking extreme value,

$$
a=\frac{\left.F\right|_{\sigma_{1}=\sigma_{f}, \varepsilon_{1}=\varepsilon_{f}}}{\left.\varepsilon_{f}\left(\partial \sigma_{1} / \partial \varepsilon_{1}\right)\right|_{\sigma_{1}=\sigma_{f}, \varepsilon_{1}=\varepsilon_{f}} \ln \left(E \varepsilon_{f} /\left(\sigma_{f}-2 \mu \sigma_{3}\right)\right)}
$$

Here, $\left.F\right|_{\sigma_{1}=\sigma_{f}, \varepsilon_{1}=\varepsilon_{f}}=\left.\varepsilon_{f}\left(\partial \sigma_{1} / \partial \varepsilon_{1}\right)\right|_{\sigma_{1}=\sigma_{f}, \varepsilon_{1}=\varepsilon_{f}}$, the specific expression of parameter $a$, can be obtained as follows:

$$
a=\frac{1}{\ln \left(E \varepsilon_{f} /\left(\sigma_{f}-2 \mu \sigma_{3}\right)\right)}
$$

Parameter $F_{0}$ is expressed as $a$ :

$$
F_{0}=\left.\sqrt[a]{a} \cdot F\right|_{\sigma_{1}=\sigma_{f}, \varepsilon_{1}=\varepsilon_{f}}
$$

\section{Damage Evolution Curve}

The following is to verify the rationality of the rock thermal damage evolution equation and constitutive model proposed in this paper based on the $\mathrm{H}-\mathrm{B}$ criterion by using the triaxial compression test results of rocks in literature $[22,23]$ at different temperatures and pressures.

The rock samples with the diameter of $50 \mathrm{~mm}$ and the length of $100 \mathrm{~mm}$ were retrieved from granite block at a depth of about 1000-1200m in the Yanzhou hard coal mine, Shandong Province, China. Through laboratory test, the average density of rock sample is $2.612 \mathrm{~g} / \mathrm{cm}^{3}$ and the average uniaxial compressive strength (UCS) is $120.37 \mathrm{MPa}$ at room temperature.

Firstly, the rock samples were heated to the temperatures of $200,400,600,800,1000$, and $1200^{\circ} \mathrm{C}$ at a rate of $10^{\circ} \mathrm{C} / \mathrm{min}$ in a high temperature furnace and then naturally cooled down to room temperature. Five rock samples were used at each temperature point, totaling 30 rock samples. Secondly, the triaxial compression tests under different confining pressures of $0,10,20,30$, and $40 \mathrm{MPa}$ were carried out on the preheated samples, using MTS815.02 electrohydraulic servo material test system. Triaxial tests were conducted under displacement control mode with a loading rate of $0.003 \mathrm{~mm} / \mathrm{s}$ to capture the postpeak behavior.

Since the stress-strain curves, damage evolution curves, and damage evolution rate curves of rocks under different confining pressures at the same temperature have similar forms, the following analysis is represented by the curve of $200^{\circ} \mathrm{C}$, as shown in Figure 2.

From Figure 2, it can be seen that the curves under different confining pressures at $200^{\circ} \mathrm{C}$ can be divided into four stages. (1) In the first stage of $A B$ segment, the rock is in the initial compaction stage. At this time, there is no microcrack in the rock, and the damage curve and damage evolution rate curve are in horizontal state. (2) In the second stage of BC segment, the rock is in the stage of steady damage propagation. Point $\mathrm{C}$ is the peak stress point of rock. In this process, the damage value and damage evolution rate of rock begin to increase gradually. It can be predicted that microcracks will occur, accumulate, and form macrocracks. When the rock reaches the peak stress, the damage value is still small, and the damage evolution rate does not reach the maximum value. After that, the damage value and damage evolution rate continue to increase. (3) In the third stage of CD segment, the rock is in the stage of accelerated damage propagation. Point $\mathrm{D}$ is the residual stress point corresponding to the maximum damage evolution rate. At this stage, the damage value and damage evolution rate increase rapidly, and macroscopic failure of rock occurs. (4) In the fourth stage of DE segment, the rock is in the stage of stable residual strength, and the damage value is still increasing until saturation, and the damage evolution rate decreases rapidly due to rock fracture.

The relationship between damage values under different confining pressures at $200^{\circ} \mathrm{C}$ and different temperatures at uniaxial compression with changes in strain is drawn as shown in Figures 3(a) and 3(b).

From Figure 3, it can be seen that the damage evolution curves under different temperature and pressure conditions are all inclined to stretch " $\mathrm{S}$ " type. With the increase of axial strain, the damage value of the rock increases from the initial value of 0 to the final value of 1 , indicating the macro deterioration of the rock. In Figure 3(a), the axial strain is in the compaction stage before 0.004 , and the confining pressure has little effect on the damage value. In Figure 3(b), the axial strain is in the horizontal stage before 0.004 . With the increase of temperature, the cumulative damage increases, which indicates that the increase of temperature accelerates the damage rate of rock. After entering the residual strength, the damage value reaches saturation and grows slowly. At this time, the rock strength enters a relatively stable state.

Considering the influence of temperature, the relationship between thermal damage and different temperature is shown in Figure 4.

It can be seen from Figure 4 that the rock thermal damage value shows exponential growth with the rise of temperature; especially, the damage value grows rapidly after $400^{\circ} \mathrm{C}$. In fact, the beginning horizontal part of the damage curve at 
TABLE 1: Peak stress and damage values of rocks under different confining pressures at $200^{\circ} \mathrm{C}$.

\begin{tabular}{|c|c|c|c|c|}
\hline Confining pressure/MPa & $\sigma_{f} / \mathrm{MPa}$ & $\left.D\right|_{\sigma=\sigma_{f}}$ & $(d D / d \varepsilon)_{\max }$ & $\left.D\right|_{(d D / d \varepsilon)_{\max }}$ \\
\hline 0 & 121.77 & 0.195 & 451.84 & 0.623 \\
\hline 10 & 199.67 & 0.202 & 289.18 & 0.617 \\
\hline 20 & 278.43 & 0.245 & 130.25 & 0.597 \\
\hline 30 & 429.04 & 0.186 & 206.52 & 0.624 \\
\hline 40 & 450.19 & 0.431 & 40.41 & 0.509 \\
\hline
\end{tabular}

TABLE 2: Peak stress and damage values of rock under uniaxial compression at different temperatures.

\begin{tabular}{|c|c|c|c|c|}
\hline Temperature $/{ }^{\circ} \mathrm{C}$ & $\sigma_{f} / \mathrm{MPa}$ & $\left.D\right|_{\sigma=\sigma_{f}}$ & $(d D / d \varepsilon)_{\max }$ & $\overline{\left.D\right|_{(d D / d \varepsilon)_{\max }}}$ \\
\hline 25 & 120.37 & 0.076 & 981.85 & 0.610 \\
\hline 200 & 121.768 & 0.195 & 451.836 & 0.623 \\
\hline 400 & 97.94 & 0.261 & 343.03 & 0.617 \\
\hline 600 & 54.62 & 0.702 & 115.89 & 0.855 \\
\hline 800 & 41.766 & 0.77 & 117.956 & 0.880 \\
\hline 1000 & 19.302 & 0.904 & 9.706 & 0.913 \\
\hline
\end{tabular}

Note: $\sigma_{f}$ is the peak stress; $\left.D\right|_{\sigma=\sigma_{f}}$ is the damage value corresponding to the peak stress; $(d D / d \varepsilon)_{\max }$ is the maximum damage evolution rate; and $\left.D\right|_{(d D / d \varepsilon)_{\max }}$ is the damage value corresponding to the maximum damage evolution rate.

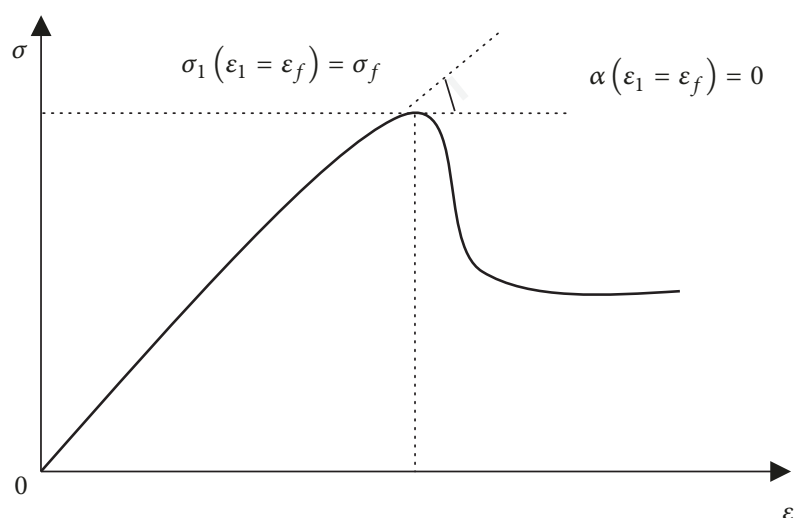

FIGURE 1: Diagram of total stress-strain of rock.

different temperature in Figure 3(b) is the thermal damage caused by temperature.

In order to analyze the influence of confining pressure and temperature on the mechanical properties of rock, the peak stress, damage value, and maximum damage evolution rate of rock under different confining pressures at $200^{\circ} \mathrm{C}$ and different temperatures in uniaxial compression are calculated as shown in Tables 1 and 2, respectively.

Meanwhile, the relationship between peak stress and maximum damage evolution rate of rock with confining pressure and temperature is plotted as shown in Figures 5(a) and $5(\mathrm{~b})$, respectively.

According to Figure 5(a), the peak stress of the rock increases exponentially with the increase of confining pressure, while the maximum damage evolution rate of the rock decreases exponentially. The fitting curves and correlation coefficients are as follows:

$$
\begin{aligned}
y & =427.9 \exp \left(-\frac{x}{20.5}\right)+21.5, \\
R^{2} & =0.75868 \\
y & =1837.3-1723.9 \exp \left(-\frac{x}{173.7}\right), \\
R^{2} & =0.93183
\end{aligned}
$$

Under the condition of high confining pressure, the number of main cracks is relatively small and there are basically no secondary cracks. Instability failure is generally difficult to occur. Confining pressure has a certain restraining effect on rock fracture.

From Figure 5(b), it can be seen that the peak stress and the maximum damage evolution rate of rocks decrease exponentially with the increase of temperature. The fitting curves and correlation coefficients are as follows:

$$
\begin{aligned}
y & =387.75-256.79 \exp \left(\frac{x}{2705.83}\right), \\
R^{2} & =0.92735 \\
y & =24.17+1028.68 \exp \left(-\frac{x}{274.88}\right), \\
R^{2} & =0.96028
\end{aligned}
$$

The main reason is that the thermal stress is inconsistent with the different expansion coefficients of mineral particles, resulting in the increase of porosity and the change of microstructure of rocks, which accelerates the failure of rocks. 


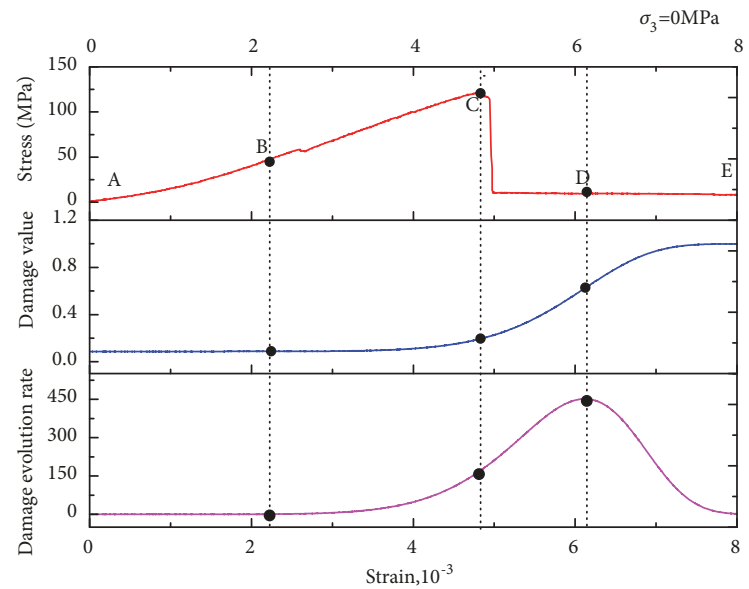

(a)

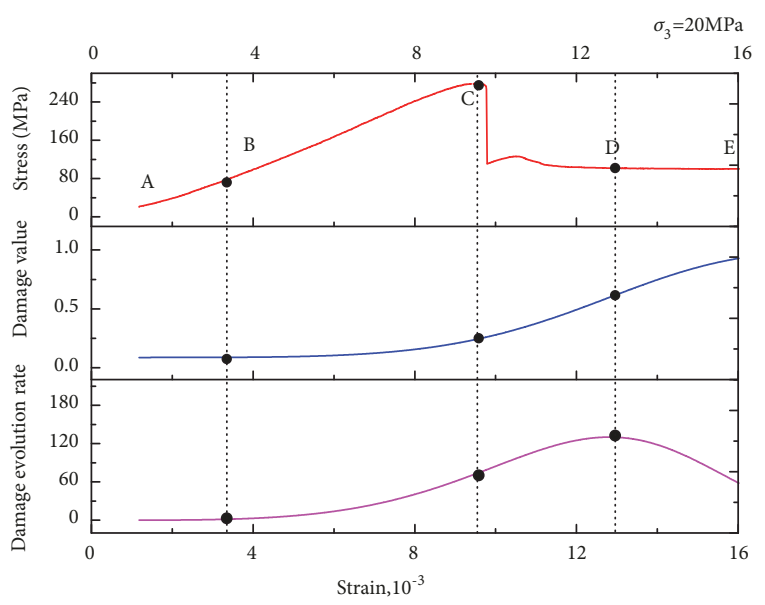

(c)

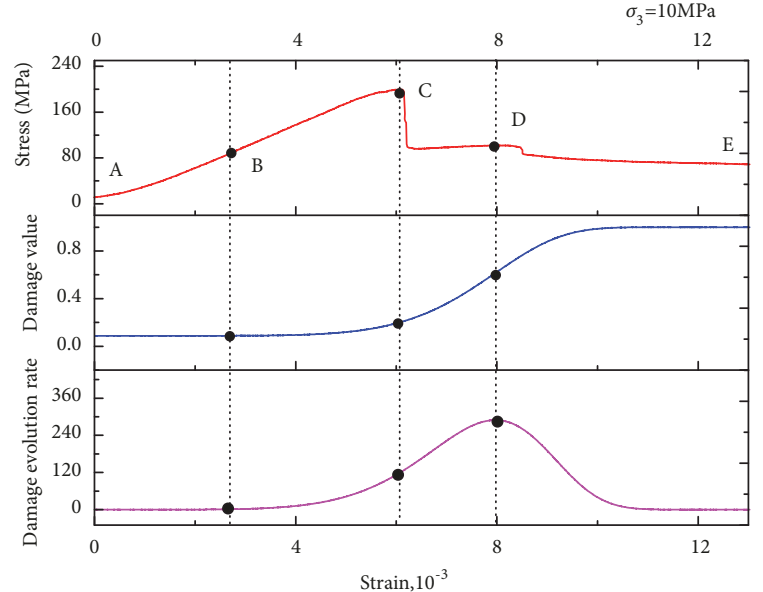

(b)

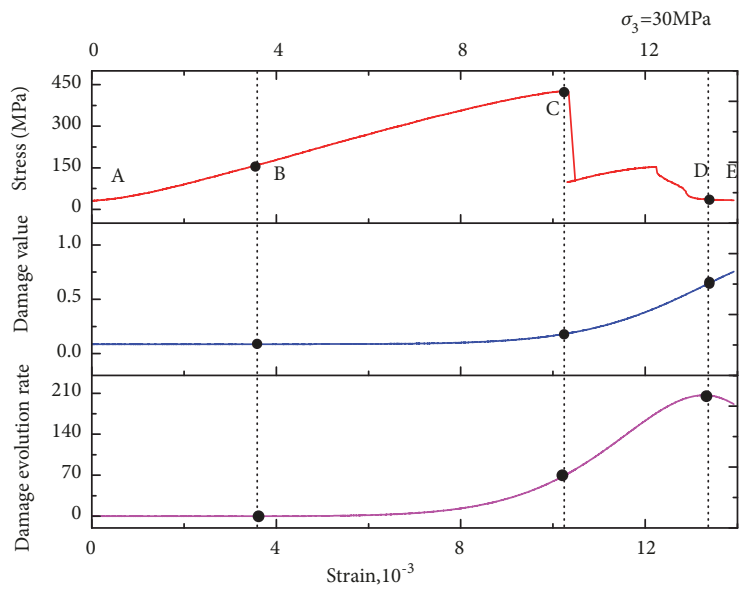

(d)

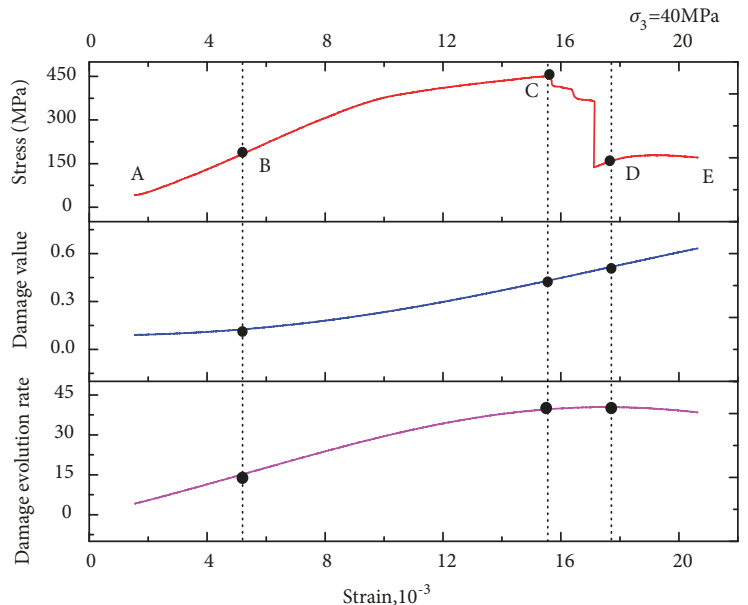

(e)

FIGURE 2: Stress-strain and damage evolution curves under different confining pressures at $200^{\circ} \mathrm{C}$. 


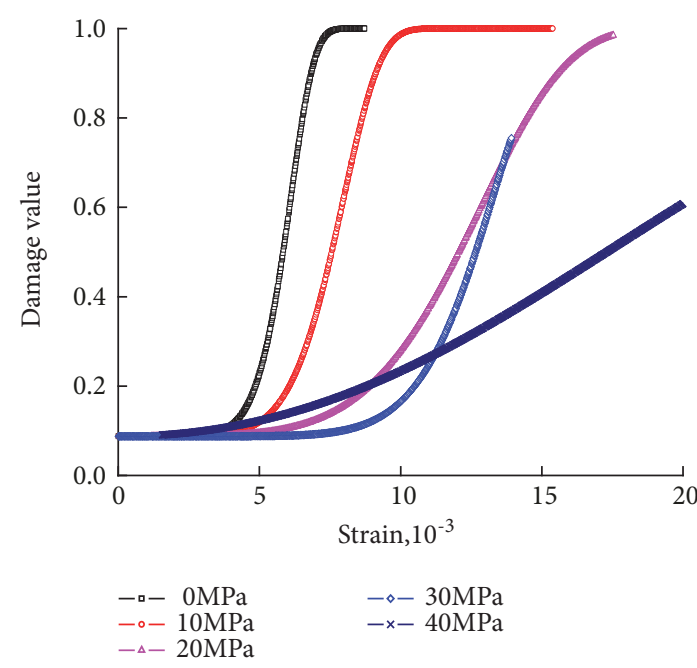

(a)

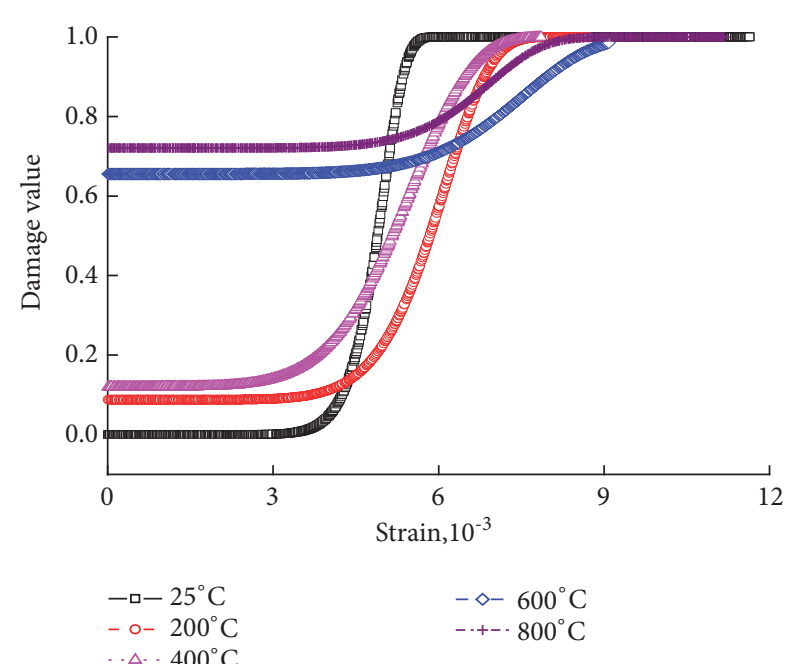

(b)

FIGURE 3: Changes of damage values with strain under different confining pressure (a) at $200^{\circ} \mathrm{C}$ and different temperature (b) at uniaxial compression.

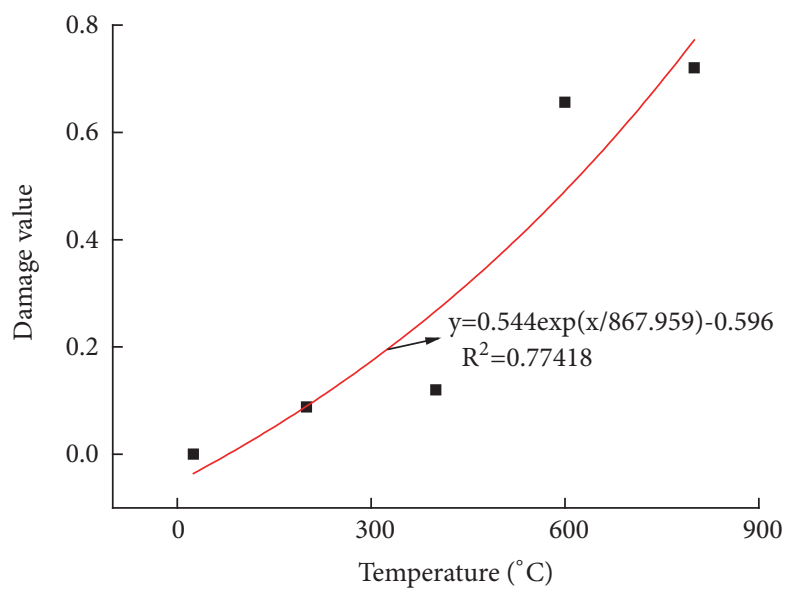

FIGURE 4: The relationship between thermal damage and different temperature.

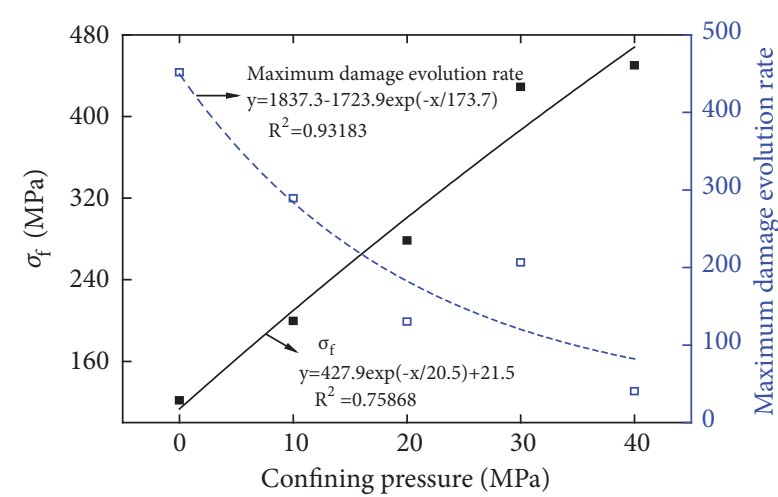

(a)

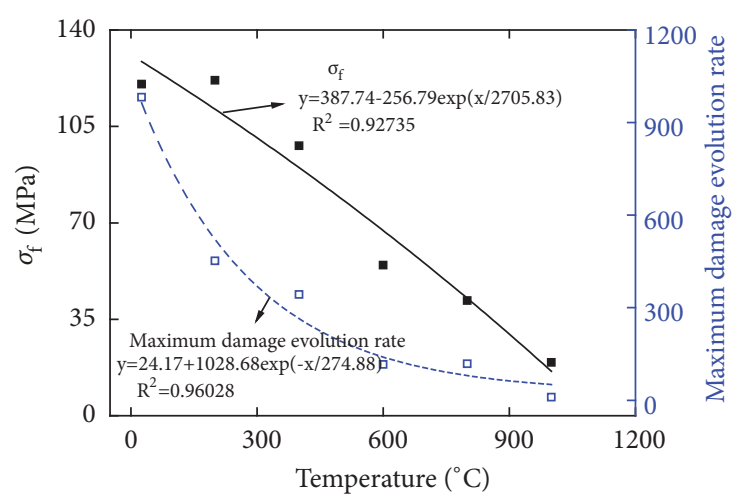

(b)

FIGURE 5: Changes of peak stress and maximum damage evolution rate of rock with confining pressure (a) and temperature (b). 


\section{Theoretical Model considering Initial Compaction Stage and Residual Strength}

Rock has compaction characteristics in the early stage of loading, and the theoretical model derived from (17) does not agree with the actual situation in the initial stage of loading. Therefore, the compaction coefficient $\mathrm{K}$ is defined as the ratio of slope to elastic modulus of rock stress-strain curve, and the ratio increases logarithmically with strain, which can be expressed as [24]

$$
\mathrm{K}= \begin{cases}\log _{a}\left[\frac{(a-1) \varepsilon}{\varepsilon_{s}}+1\right] & \varepsilon<\varepsilon_{s} \\ 1 & \varepsilon \geq \varepsilon_{s}\end{cases}
$$

where a is the constant obtained from the experiment and $\varepsilon_{\mathrm{s}}$ is the strain corresponding to the yield stress.

Equation (17) can be modified as follows:

$$
\begin{aligned}
\sigma_{1} & =K E_{T} \varepsilon_{1} \\
& \cdot \exp \left\{-\left[\frac{m \sigma_{c} \sigma_{1} E_{T} \varepsilon_{1}}{F_{0}\left(\sigma_{1}-2 \mu \sigma_{3}\right)}+\frac{\left(\sigma_{1}-\sigma_{3}\right)^{2} E_{T}^{2} \varepsilon_{1}^{2}}{F_{0}\left(\sigma_{1}-2 \mu \sigma_{3}\right)^{2}}\right]^{a}\right\} \\
& +\mu\left(\sigma_{2}+\sigma_{3}\right)
\end{aligned}
$$

On the other hand, considering that some of the pressure and shear stress will continue to be transmitted after the failure of rock microelements, and with the influence of confining pressure, residual strength gradually becomes the main factor affecting the postpeak section of rock stressstrain curve. Therefore, the damage variable correction factor $\delta$ [25-27], which is related to residual strength, is introduced. The damage variable is modified, i.e., $\sigma^{*}=\sigma /(1-\delta D)$; in general, $\delta$ is taken between $(0-1)$.

After modification, (29) can be revised as follows:

$$
\begin{aligned}
\sigma_{1} & =K E_{T} \varepsilon_{1} \exp \{1-\delta \\
& \left.+\delta\left[\frac{m \sigma_{c} \sigma_{1} E_{T} \varepsilon_{1}}{F_{0}\left(\sigma_{1}-2 \mu \sigma_{3}\right)}+\frac{\left(\sigma_{1}-\sigma_{3}\right)^{2} E_{T}^{2} \varepsilon_{1}^{2}}{F_{0}\left(\sigma_{1}-2 \mu \sigma_{3}\right)^{2}}\right]^{a}\right\} \\
& +\mu\left(\sigma_{2}+\sigma_{3}\right)
\end{aligned}
$$

The revised statistical constitutive model of rock thermal damage is modified by choosing the triaxial compression test data of rock at $200^{\circ} \mathrm{C}$. Figure 6 shows the test curves, primitive theoretical curves, and modified theoretical curves of rocks under different confining pressures of $200^{\circ} \mathrm{C}$.

It can be seen that the primitive theoretical curve cannot well reflect the initial compaction stage of rock, and the postpeak curve does not consider the residual strength. The theoretical curve of the revised rock thermal damage constitutive model is in good agreement with the test curve and can better reflect the compressive and residual strength characteristics of rock, which verifies the rationality of the model.
The value of the correction coefficient $\delta$ will affect the theoretical curve. The stress-strain relationship of different damage correction coefficient $\delta$ is plotted when the temperature is $200^{\circ} \mathrm{C}$, and the confining pressure is $20 \mathrm{MPa}$, as shown in Figure 7.

The change of the correction coefficient hardly changes the curve of the front part of the rock peak, but it is obvious to the curve of the back part of the rock peak, which shows that $\delta$ can reflect the change characteristics of the residual strength well. When $\delta$ increases from 0.75 to 0.95 , the residual strength decreases by $15.7 \%$, which indicates that only the residual strength is sensitive to $\delta$, and the damage correction coefficient mainly reflects the residual strength characteristics of rock.

\section{Conclusion}

Based on the thermal damage theory and the H-B strength criterion, a thermomechanical coupled thermal damage constitutive model is established. At the same time, the theoretical model is modified by considering the compaction coefficient and residual strength correction coefficient; the rationality of the modified model is verified by experimental data. The following conclusions are obtained as follows:

(1) According to the characteristics of rock damage evolution, the stress-strain curve of rock can be divided into four stages: initial compaction, stable damage expansion, damage strengthening expansion, and damage failure.

(2) The peak stress of rock increases exponentially with the increase of confining pressure, and the maximum damage evolution rate decreases exponentially with the increase of confining pressure, which indicates that the confining pressure delays the development of cumulative damage.

(3) The peak stress and the maximum damage evolution rate of rocks decrease exponentially with the increase of temperature, which indicates the temperature accelerates the damage of rocks. The first half of rock damage is caused by temperature, and the damage value increases with the increase of temperature.

(4) The theoretical model is modified by introducing rock compaction coefficient $\mathrm{K}$ and residual strength correction coefficient $\delta$. The modified theoretical curve well reflects the characteristics of rock compaction stage and residual strength as well, which is in good agreement with the experimental curve. The research results provide a reference for the constitutive model of rock thermal damage in deep engineering.

\section{Data Availability}

The data used to support the fndings of this study are included within the article.

\section{Conflicts of Interest}

The authors declare that there are no conflicts of interest regarding the publication of this paper. 


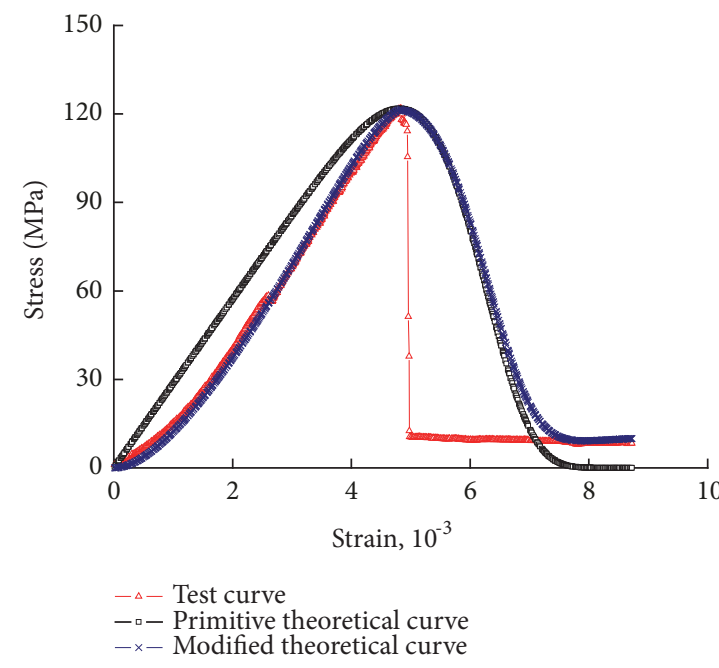

(a) $\sigma_{3}=0 \mathrm{MPa}$

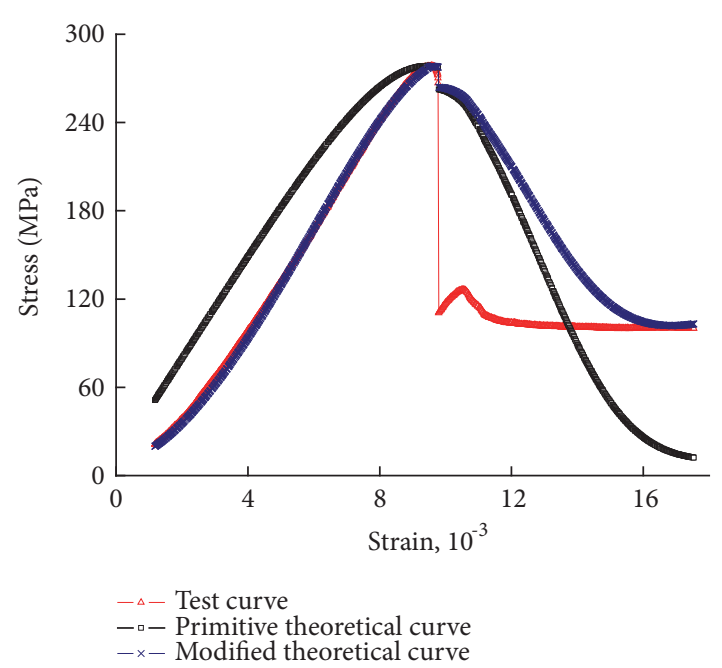

(c) $\sigma_{3}=20 \mathrm{MPa}$

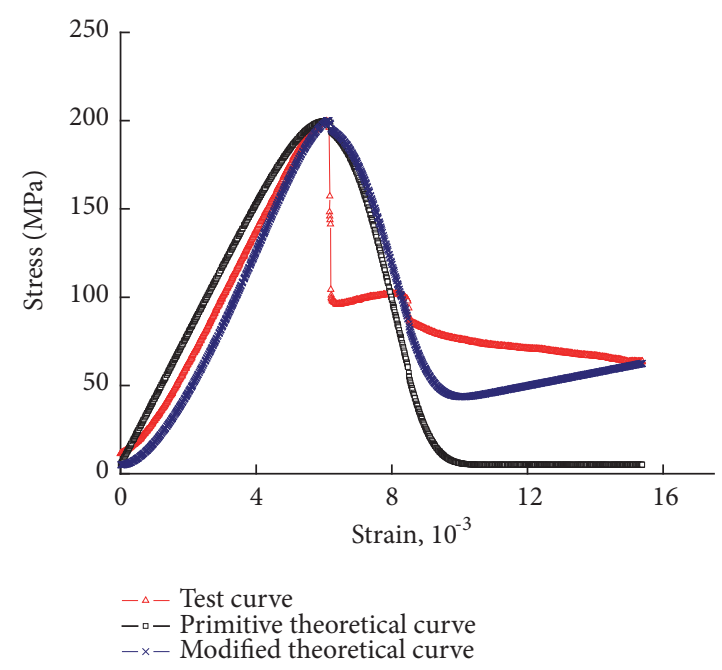

(b) $\sigma_{3}=10 \mathrm{MPa}$

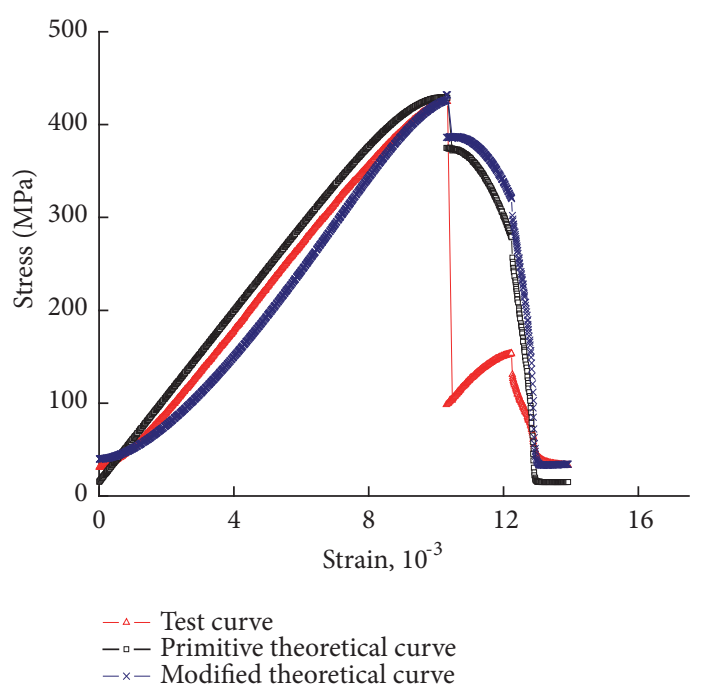

(d) $\sigma_{3}=30 \mathrm{MPa}$

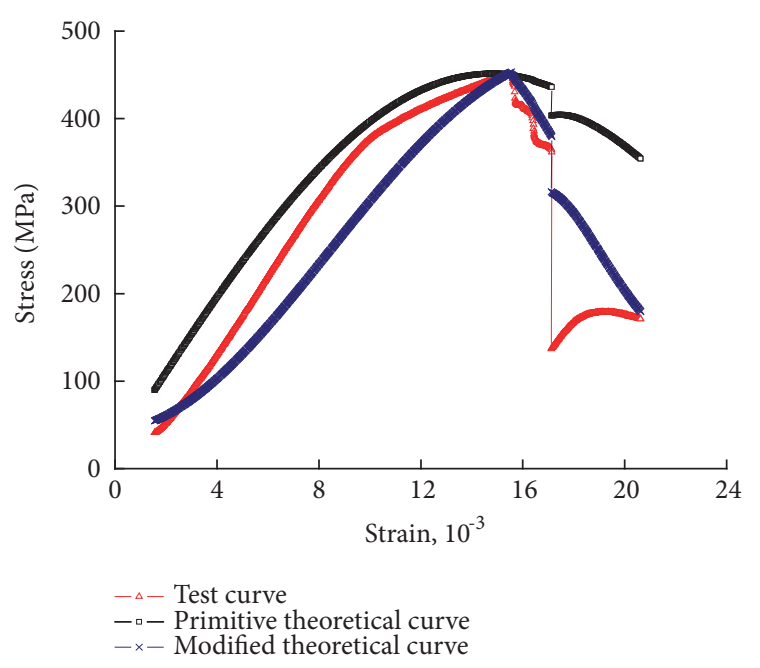

(e) $\sigma_{3}=40 \mathrm{MPa}$

Figure 6: Theoretical and test curves under different confining pressures at $200^{\circ} \mathrm{C}$. 


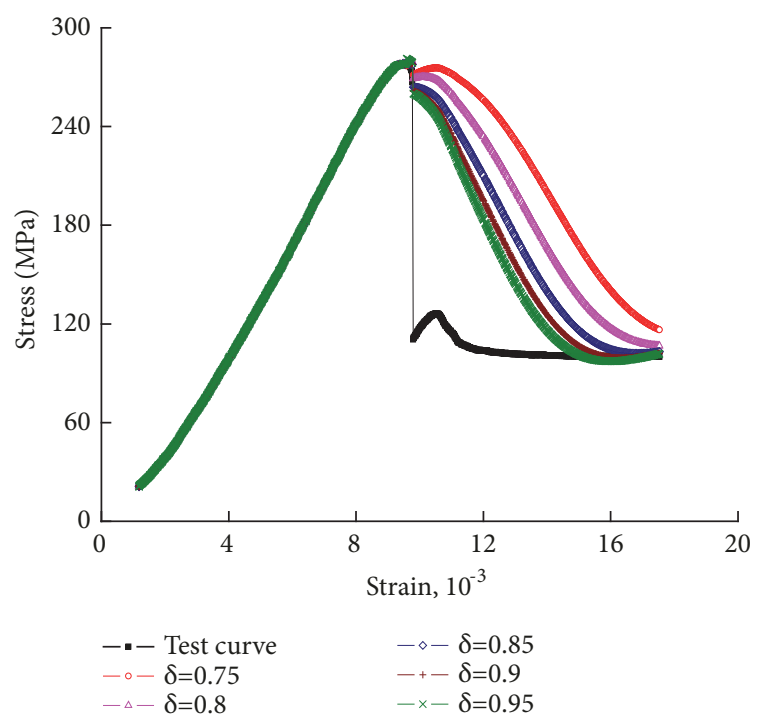

FIGURE 7: The relationship between damage correction factor and stress-strain curve.

\section{Acknowledgments}

This work was supported by the National Natural Science Foundation of China (Grant No. 11802145) and the Opening Fund of State Key Laboratory for Geomechanics and Deep Underground Engineering of China University of Mining and Technology (Grant No. SKLGDUEK1204).

\section{References}

[1] W. G. Cao, M. H. Zhao, and C. X. Liu, "Rock damage softening model based on Weibull distribution and its correction method," Journal of Rock Mechanics and Engineering, vol. 23, no. 19, pp. 3226-3231, 2004.

[2] Z. H. Fang, "Study on rock damage constitutive model based on Mohr-Coulomb criterion," Mining Engineering Research, vol. 32, no. 1, pp. 7-13, 2017.

[3] J. Xu, S. C. Li, Y. B. Liu et al., "Rock damage constitutive model based on Drucker-Prager criterion," Journal of Southwest Jiaotong University, vol. 42, no. 3, pp. 278-282, 2007.

[4] E. Hoek and E. T. Brown, Undergroud Excavations in Rock, Institution of Mining and Metallurgy, London, UK, 1980.

[5] J. B. Wang, X. R. Liu, and P. Li, "Statistical constitutive, model of rock damage softening," Journal of Lanzhou University, vol. 47, no. 3, pp. 24-28, 2011.

[6] R. S. Yu, Y. Yang, and D. L. Xu, "Hoek-Brown strength criterion applied in estimating mechanical parameters of deep rock mass," Journal of Yangtze Academy of Sciences, vol. 35, no. 1, pp. 123-127, 2018.

[7] S. T. Yu, H. W. Deng, and Y. N. Zhang, "Constitutive relationship of rock damage under confining pressure and temperature," Journal of Railway Science and Engineering, vol. 15, no. 4, pp. 1-9, 2018.

[8] W. F. Chen and D. J. Han, Plasticity for Structural Engineers, Springer, New York, NY, USA, 1988.

[9] L. Y. Zhang, Damage Evolution and Fracture Mechanism of Mudstone under High Temperature, China University of Mining and Technology, Xuzhou, China, 2013.
[10] X. Z. Meng, Damage Constitutive Model of Porous Rock under Freeze-Thaw-Load, Xian University of Science and Technology, Xi'an, China, 2018.

[11] M. Xia, C. Zhao, and B. E. Hobbs, "Particle simulation of thermally-induced rock damage with consideration of temperature-dependent elastic modulus and strength," Computers \& Geosciences, vol. 55, pp. 461-473, 2014.

[12] R. D. Dwivedia, R. K. Goela, V. V. R. Prasada et al., "Thermomechanical properties of Indian and other granites," International Journal of Rock Mechanics \& Mining Sciences, vol. 45, no. 3, pp. 303-315, 2008.

[13] S. C. Li, J. Xu, and K. G. Li, "Constitutive model of rock damage based on modified initial damage coefficient," Journal of Sichuan University, vol. 39, no. 6, pp. 41-44, 2007.

[14] Y. S. Yang, Q. F. Yin, C. J. Feng et al., "Study on statistical damage constitutive model of rocks considering damage correction," Journal of Anhui University of Technology, vol. 38, no. 4, pp. 7074, 2018.

[15] M. Cai, P. K. Kaiser, Y. Tasaka, and M. Minami, "Peak and residual strength of jointed rock masses and their determination for engineering design," Rock Mechanics, vol. 32, no. 4, pp. 259267, 2007.

[16] T. Wen, H. M. Tang, J. W. Ma et al., "Rock deformation process simulation considering initial damage and residual strength," Geosciences, vol. 41, no. 2, pp. 652-663, 2018.

[17] X. Xu, F. Gao, and Z. Zhang, “Thermo-mechanical coupling damage constitutive model of rock based on the Hoek-Brown strength criterion," International Journal of Damage Mechanics, vol. 27, no. 8, pp. 1213-1230, 2017.

[18] P. Xie, Fractal-Introduction to Rock Mechanics, Science Press, Beijing, China, 1996.

[19] Q. S. Liu and X. C. Xu, "Damage analysis of brittle rock under temperature," Journal of Rock Mechanics and Engineering, vol. 19, no. 4, pp. 408-411, 2000.

[20] H. M. Zhang and G. S. Yang, "Study on rock damage model under freeze-thaw and load coupling," Journal of Rock Mechanics and Engineering, vol. 29, no. 3, pp. 471-476, 2010.

[21] J. A. Lemaitre, "How to use damage mechanics," Nuclear Engineering and Design, vol. 80, no. 2, pp. 233-245, 1984.

[22] X. L. Xu, F. Gao, and Z. Z. Zhang, "Triaxial compression test of granite after high temperature action," Geotechnical Mechanics, vol. 35, no. 11, pp. 3176-3183, 2014.

[23] X. Xu and M. Karakus, "A coupled thermo-mechanical damage model for granite," International Journal of Rock Mechanics and Mining Sciences, vol. 103, pp. 195-204, 2018.

[24] X. S. Liu, J. G. Ning, Y. L. Tan, and Q. H. Gu, "Damage constitutive model based on energy dissipation for intact rock subjected to cyclic loading," International Journal of Rock Mechanics and Mining Sciences, vol. 85, pp. 27-32, 2016.

[25] Y. Q. Zhou, Q. Sheng, X. L. Leng et al., "Statistical model of rock elastic damage considering the threshold effect of residual strength," Journal of Yangtze Academy of Sciences, vol. 33, no. 3, pp. 48-53, 2016.

[26] R. L. Cao, S. H. He, J. Wei, and F. Wang, "Statistical constitutive model of rock damage softening based on residual strength modification," Geotechnical Mechanics, vol. 34, no. 6, pp. 16521667, 2013.

[27] H. M. Zhang, X. N. Liu, C. Peng et al., "Constitutive model of rock damage considering residual strength," Mechanics and Practice, vol. 40, no. 1, pp. 51-55, 2018. 


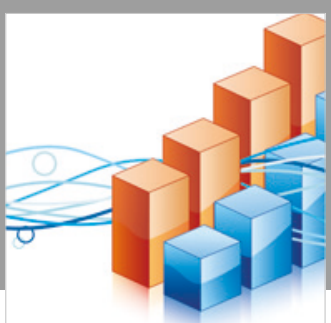

Advances in

Operations Research

\section{-n-m}
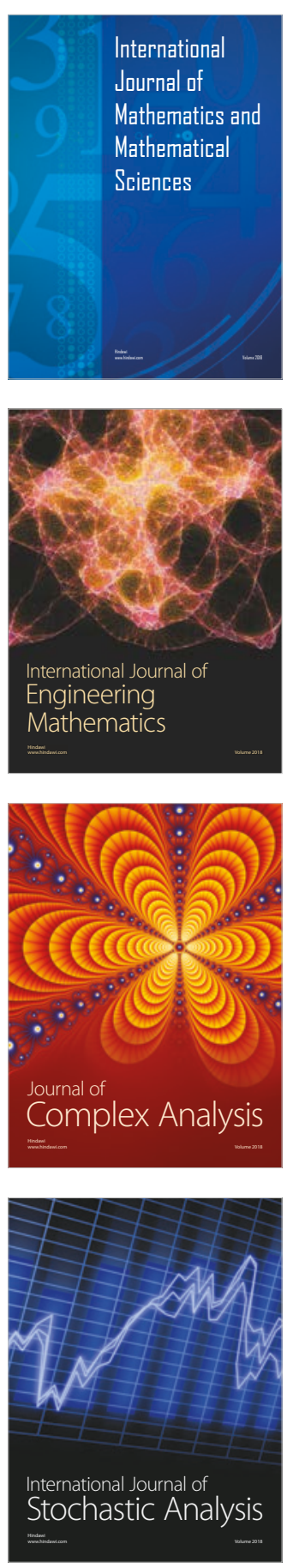
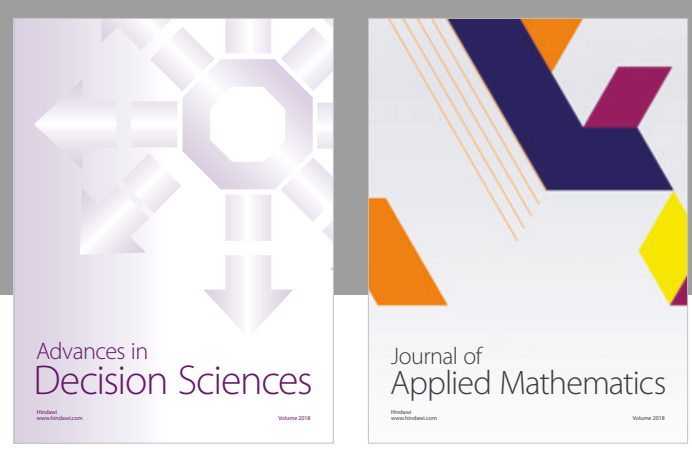

Journal of

Applied Mathematics
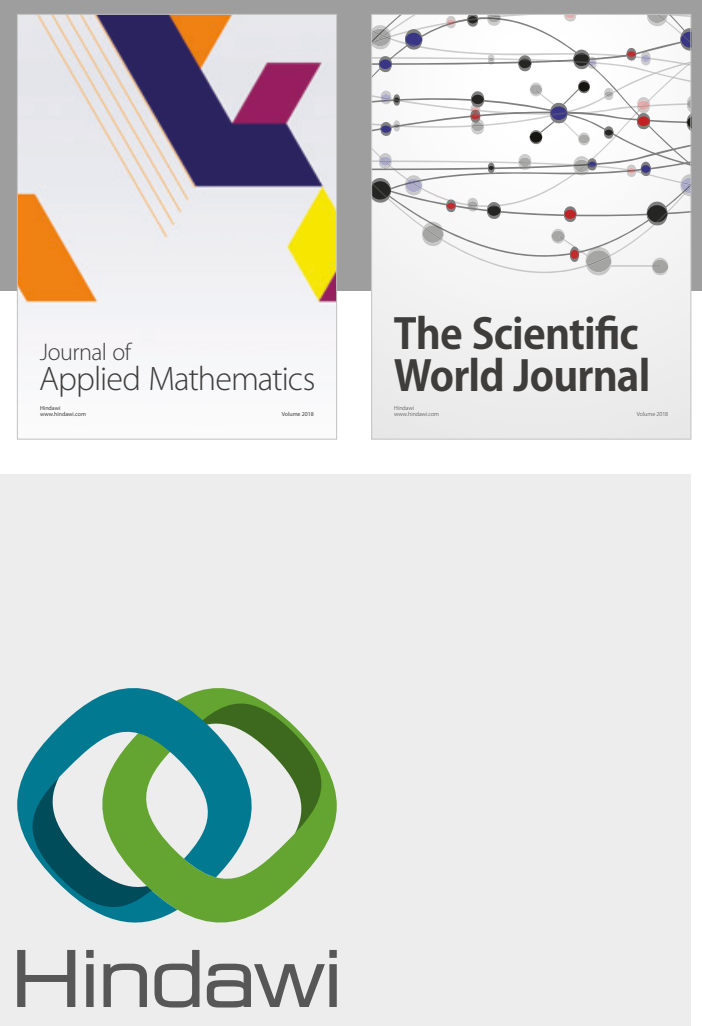

Submit your manuscripts at

www.hindawi.com

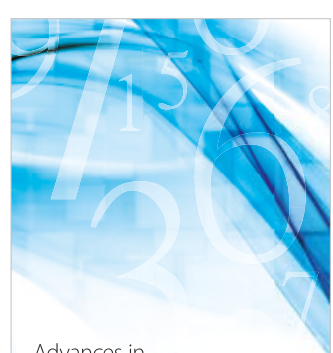

Advances in
Numerical Analysis
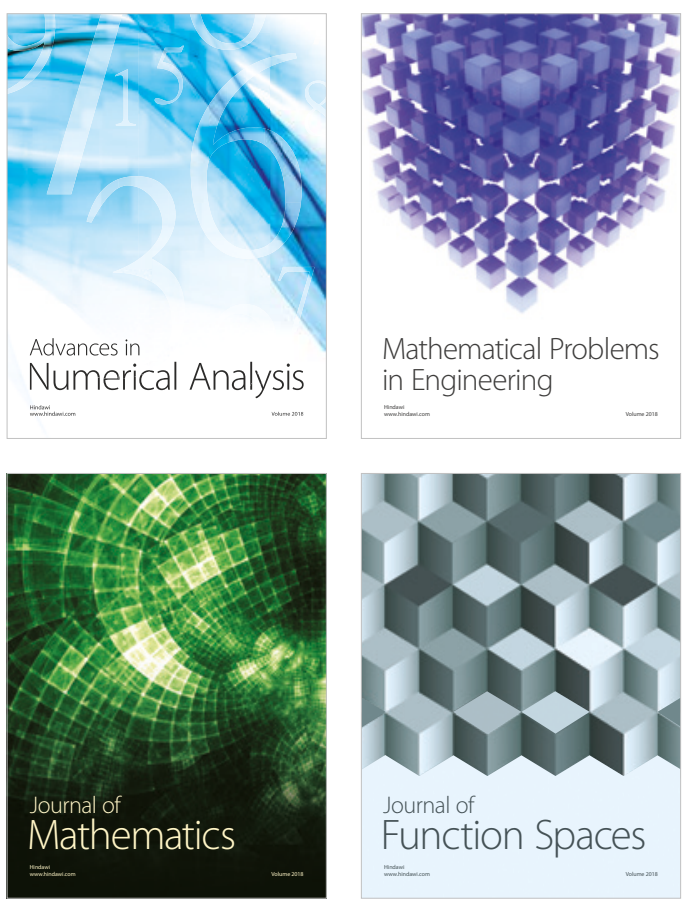

Mathematical Problems in Engineering

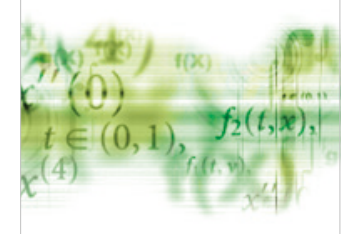

International Journal of

Differential Equations

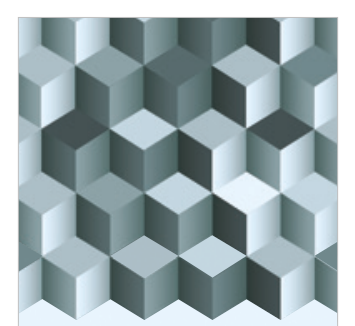

Journal of

Function Spaces

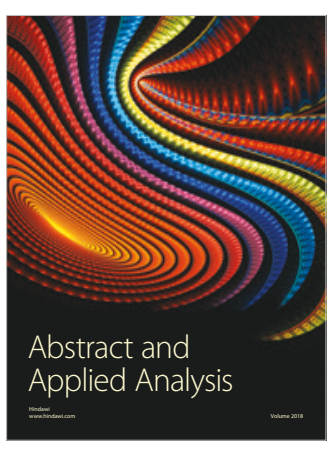

The Scientific

World Journal

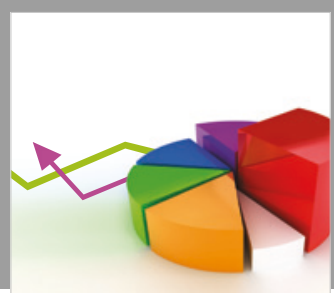

Journal of

Probability and Statistics
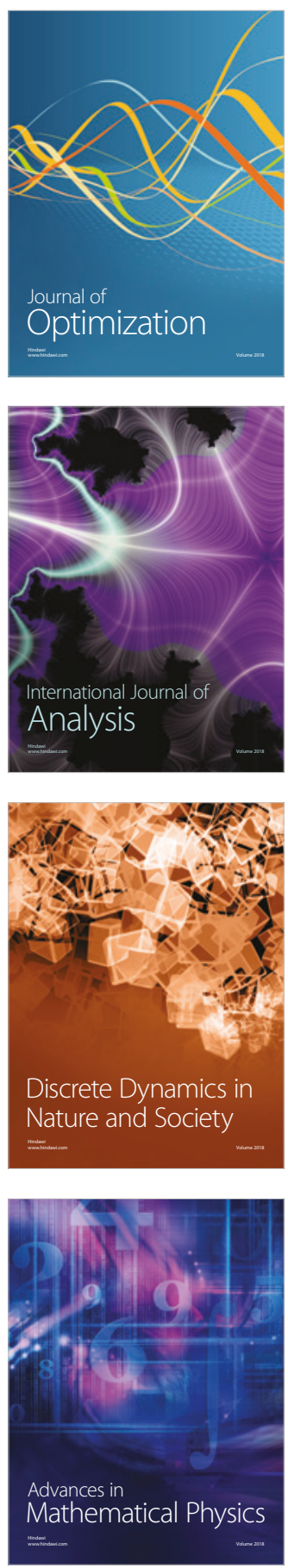